\title{
The application of hyperspectral image techniques on MODIS data for the detection of oil spills in the $\operatorname{RSA}^{1}$
}

\author{
Fahad Alawadi ${ }^{*}$, Carl Amos ${ }^{\mathrm{b}}$, Valborg Byfield ${ }^{\mathrm{c}}$, Peter Petrov ${ }^{\mathrm{a}}$ \\ ${ }^{a}$ Regional Organization for the Protection of Marine Environment, Kuwait; \\ ${ }^{b}$ School of Ocean and Earth Science, University of Southampton, Waterfront Campus, Empress \\ Dock, Southampton, S014 3ZH, UK; \\ 'NERC Strategic Research Division, National Oceanography Centre, Empress Dock, Southampton, \\ S014 3ZH, UK
}

\begin{abstract}
Oil spills pose a serious threat to the sensitive marine ecosystem of the RSA. The study aims to detect and identify oil spills using remote sensing data provided by ROPME MODIS receiving station. MODIS data of confirmed incidents of oil spills via in-situ observations were processed to produce radiometrically corrected L1B data. Algal mats were further eliminated as look-alike, when the distinct oil pattern was not visible in the standard MODIS algorithm for Chlorophyll a. Shape analysis based on the operators' prior knowledge of the region was also used as a method for discriminating oil from other look-alikes. Oil spills exhibit different levels of contrast in relation to the viewing angle geometry and sun position. The Spectral Contrast Shift (SCS) is an empirical relationship that was derived to identify sea surface patterns including oil spills using the maximum and minimum spectral radiance values at the $250 \mathrm{~m}$ spatial resolution bands. Results were combined with GIS based information of oil platform locations and daily tanker routes to aid interpretation and improve the probability for an accurate identification of oil spills, and avoiding false positives.
\end{abstract}

Keyword List: Remote Sensing; MODIS; Oil Spills, Hyperspetcral; GIS, Spectral Contrast Shift; Sun Glint; ROPME Sea Area.

1 The Regional Organization for the Protection of the Marine Environment (ROPME) Sea Area (RSA) is the sea area surrounded by the eight Member States of ROPME: Bahrain, I.R. Iran, Iraq, Kuwait, Oman, Qatar, Saudi Arabia and the United Arab Emirates. RSA is defined as extending between the following geographic latitudes and longitudes, respectively: $16^{\circ} 39^{\prime} \mathrm{N}, 5^{\circ} 3^{\prime} 30^{\prime \prime} \mathrm{E}$; $16^{\circ} 00^{\prime} \mathrm{N}, 53^{\circ} 25^{\prime} \mathrm{E} ; 17^{\circ} 00^{\prime} \mathrm{N}, 56^{\circ} 30^{\prime} \mathrm{E} ; 20^{\circ} 30^{\prime} \mathrm{N}, 60^{\circ} 00^{\prime} \mathrm{E} ; 25^{\circ} 04^{\prime} \mathrm{N}, 61^{\circ} 25^{\prime} \mathrm{E}$ (Kuwait Action Plan, 1978).

*1a2x07@soton.ac.uk; fahad@ropme.org

Remote Sensing for Environmental Monitoring, GIS Applications, and Geology VIII, edited by Ulrich Michel, Daniel L. Civco, Manfred Ehlers, Hermann J. Kaufmann, Proc. of SPIE Vol. 7110, 71100Q - @ 2008 SPIE · CCC code: 0277-786X/08/\$18 - doi: 10.1117/12.799374 


\section{INTRODUCTION}

The RSA is bound by the major oil producing countries of the world, where the overall merchant shipping amounts to $1.79 \%$ of the world's total shipping activity [12]. This activity, has led to the frequent occurrences of oil leak incidents, and is therefore, putting the region under immense environmental stress. Oil spills are expected to have detrimental effects on the region's ecosystem due to the relative shallow bathymetry. As a result, ROPME has decided to explore options offered by remote sensing techniques for early warning detection of oil spills in the region.

In 2003, ROPME established a Moderate Resolution Imaging Spectroradiometer (MODIS) direct broadcast receiving station to perform near real time monitoring of the RSA. The MODIS instrument operates on both the Terra and Aqua spacecrafts. It has a viewing swath width of $2,330 \mathrm{~km}$ and views the entire surface of the Earth every one to two days. Its detectors measure 36 spectral bands between 0.405 and $14.385 \mu \mathrm{m}$, and it acquires data at three spatial resolutions -$250 \mathrm{~m}, 500 \mathrm{~m}$, and $1000 \mathrm{~m}[14]$.

\begin{tabular}{|c|c|c|c|} 
Band & Bandwidth $^{1}$ & Spectral Radiance $^{\underline{2}}$ & Required SNR $^{3}$ \\
\hline 1 & $620-670$ & 21.8 & 128 \\
\hline 2 & $841-876$ & 24.7 & 201 \\
\hline 20 & $3.660-3.840$ & $0.45(300 \mathrm{~K})$ & 0.05 \\
\hline 23 & $4.020-4.080$ & $0.79(300 \mathrm{~K})$ & 0.07 \\
\hline 31 & $10.780-11.280$ & $9.55(300 \mathrm{~K})$ & 0.05 \\
\hline 32 & $11.770-12.270$ & $8.94(300 \mathrm{~K})$ & 0.05 \\
\hline
\end{tabular}

Table (1). The MODIS bands that are used in this paper

1 Bands 1 and 2 are in $\mathrm{nm}$; rest in $\mu \mathrm{m}$

$\underline{2}$ Values are $\left(W / m^{2}-\mu m-s r\right)$

$\underline{3} S N R=$ Signal-to-noise ratio

Generally the use of optical passive sensors, unlike active microwave sensors, are not commonly used for the detection of oil marine slicks. The reasons being that they are seen to be deficient in several ways: (1) limited revisiting times; (2) relatively weak response to oil; (3) signal attenuation during certain atmospheric conditions such as cloud cover and night overpasses [4].

Through the operation of the ROPME station, MODIS has demonstrated the potential to perform daily monitoring of coastal zones in search of oil spills [2]. It has proved to be one of the most viable and cost-effective remote sensing devices for the detection of oil spills in a region as large as ROPME which covers an area of about 464,392 $\mathrm{km}^{2}$.

MODIS success was largely attributed to the fact that RSA is $\approx 80 \%$ cloud-free and enjoys a relative calm sea state. However, a number of atmospheric phenomena in the region, such as clouds and dust storms present challenges that can influence the detection of the spills. The RSA has the largest aerosol burdens in the world with frequent dust storms, smoke advection from the Indian subcontinent, and its own high emission rates of pollution from the petroleum industry and local construction [6].

MODIS unlike SeaWiFS cannot point away from nadir as it approaches the equator, and will therefore suffer from sun glint contamination (the specular reflection of sun light off the sea surface). The signal due to sun glint is much greater than the sun light reflected from below the surface that retrieval of information about in-water constituents by direct measurement is severely compromised, and often impossible. 
Many papers have been written on the use of remote sensing methods for the detection of oil spills. This paper will attempt to introduce new methods compatible with the daily monitoring and operational use of MODIS direct broadcast data. The analysis was based on two confirmed oil spill incidents in the RSA. The first incident was captured by the Terra satellite under no sun glint conditions while the other was captured by the Aqua satellite within a sun glint region.

\section{METHOD}

The discrimination of oil spills is undertaken at the highest spatial resolution $(250 \mathrm{~m})$ of MODIS L1 ${ }^{1}$ since most occurring oil spills cover a region of not more than few kilometers in size. Two pre-processing steps were undertaken on the L1B $250 \mathrm{~m}^{\text {bands }}{ }^{2}$ to inverse the data contrast in order to provide the investigator with an improved visual capability to discriminate between the surface water phenomena, such as ships, oil platforms, algal mats and oil spills from the dark water background. These are

$$
(L 2 / L 1)-L 2
$$

$$
L 1 / L 2
$$

where L1 and L2 are radiances at $645 \mathrm{~nm}$ and $869 \mathrm{~nm}$ respectively ${ }^{3}$. Equ. (2) appeared to provide better contrast when suspected patches were observed within the vicinity of sun glint.

A number MODIS Level $2\left(\mathrm{~L}^{4}\right)$ products were generated at $250 \mathrm{~m}$ resolution to support our decision-making process in either eliminating or confirming our observed patches as oil spills or as look-alikes. Amongst the products generated were; Sea Surface Temperature maps using $11-12 \mu \mathrm{m}$ channels (SST)

where

$$
S S T=a+b T 31+c(T 31-T 32) T_{\text {oisst }}+d(T 31-T 32)(\sec (\theta)-1)
$$

respectively.

$$
\text { T31, T32 = Brightness temperatures measured in bands } 31(11 \mu \mathrm{m}) \text { and } 32(12 \mu \mathrm{m})
$$

$\mathrm{T}_{\text {oisst }}=$ First guess SST, taken from NOAA Optimum Interpolation SST (OISST).

$\Theta=$ Satellite zenith angle.

$a, b, c$ and $d$ are Platform (Terra or Aqua) dependent coefficients.

and Sea Surface Temperature maps using 3.9-4 $\mu \mathrm{m}$ channels (SST4)

$$
\text { SST4 }=a+b T 20+c T 23
$$

where

T20, T23 $=$ Brightness temperatures measured in bands $20(3.9 \mu \mathrm{m})$ and $23(4 \mu \mathrm{m})$ respectively. $\mathrm{a}, \mathrm{b}$ and $\mathrm{c}=$ Platform (Terra or Aqua) dependent coefficients.

to investigate the possibility of any temperature variation between the patches and its surroundings.

1 Level 1B is the radiometric calibration of data from the MODIS sensors on the EOS-Terra and EOS-Aqua satellites. This calibration is performed on a pixel-by-pixel basis for each of the MODIS' 36 spectral bands.

2 Histogram stretching operation was performed to enhance contrast.

3 Non valid data were set to no-value data.

4 Oceanic optical properties and various derived geophysical products from the observed top-of-atmosphere (TOA) radiances. 
Chlorophyll-a Concentration (Chlor-a), which can be used as an indicator for plankton biomass or to trace oceanographic currents, jets and plumes [8].

where

$$
\log 10(\text { Chlor-a })=0.283-2.753 R+1.457 R^{2}+0.659 R^{3}-1.403 R^{4}
$$

$10^{\mathrm{R}}=\max \left(\mathrm{R}_{\mathrm{rs}}(443), \mathrm{R}_{\mathrm{rs}}(488)\right) / \mathrm{R}_{\mathrm{rs}}(551)$

$\mathrm{R}_{\mathrm{rs}}$ (remote sensing reflectance) $=\mathrm{Lw}$ (water leaving radiance) / Ed ( Downward irradiance just above sea surface) for a particular band.

Finally, the normalized water-leaving radiance (nlw)

$$
n L w \_n n n=L w \_n n n /\left(t 0 \mathrm{mu} 0 f_{s o l}\right) * f o o b * b r d f \_n n n
$$

where

$$
\begin{aligned}
& \text { Lw_nnn=water leaving radiance at nnn wavelength. } \\
& \text { t0=t_oz_sol_nnn * t_sol_nnn. } \\
& \text { t_sol_nnn }=\text { diffuse transmittance from Sun to sensor. } \\
& \text { t_oz_sol_nnn }=\text { transmittance from sun to sensor through ozone layer. } \\
& \text { mu } 0=\text { cos(solz). } \\
& \text { fsol }=\text { earth-sun distance correction. } \\
& \text { foob = correction for out-of-band response. } \\
& \text { brdf_nnn }=\text { bi-directional reflectance correction. }
\end{aligned}
$$

The difference in nlw at the 869nm and 645nm bands (nlw_869, nlw_645) was determined as follows

$$
n l w \_869-n l w \_645
$$

Although equation (7) is not a standard MODIS product, it may still prove useful as a high resolution proxy for turbidity which can be related to concentrations of suspended matter or other scattering sources [13]. Suspended oil mixture will scatter light in a similar manner to other suspended particles, and thus increase water leaving radiance in the red and near infra-red [16].

A new empirical classification method, the Spectral Contrast Shift (SCS) was derived to link the radiometric difference of spectral ratios between the maximum and minimum values of the $250 \mathrm{~m}$ resolution bands

$$
S C S=\left|\left(L_{\max 2} / L_{\max 1}\right)-\left(L_{\min 2} / L_{\min 1}\right)\right|
$$

where $\mathrm{L}_{\max 2}$ and $\mathrm{L}_{\min 2}$ are the maximum and minimum spectral radiance values at $869 \mathrm{~nm}$ and $\mathrm{L}_{\max 1}$ and $\mathrm{L}_{\min 1}$ are the maximum and minimum spectral radiance values at $649 \mathrm{~nm}$.

Equation (8) is similar to two standard classification methods: (1) the Parallelepiped classification shown in Figure 1. which uses the threshold of each class signature to determine if a pixel is within a class or not [15]; and (2) the Spectral Angle Mapper (SAM) shown in Figure 2. which measures the spectral similarity by calculating the angle between the reference and target spectra, treating them as vectors in n-dimensional space where the small angles between the two spectra indicate high similarity and high angles indicate low similarity[9]. 


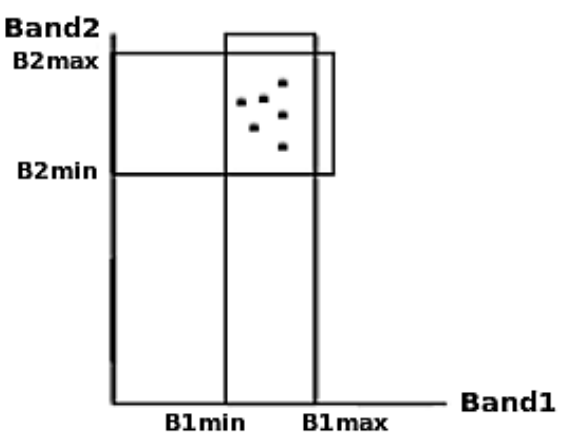

Figure 1. Parallelepiped classification.

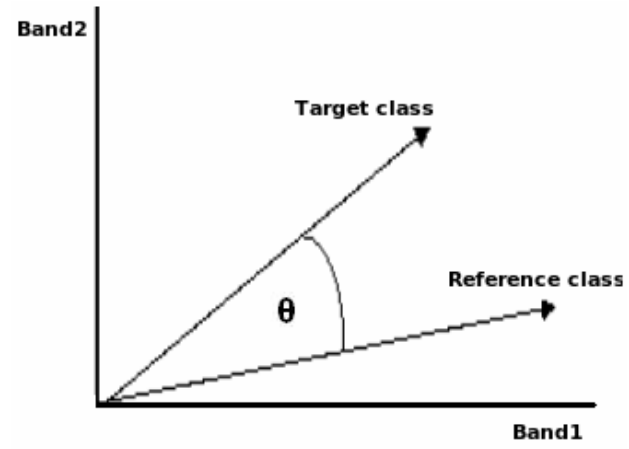

Figure 2. Spectral Angle Mapper (SAM).

The (SCS) value can be interpreted as shown in Figure 3. as a measure of the angle between two straight vectors pointing to points $\left(\mathrm{B}_{2 \max }, \mathrm{B}_{1 \max }\right)$ and $\left(\mathrm{B}_{2 \min }, \mathrm{B}_{1 \min }\right)$ respectively from the origin.

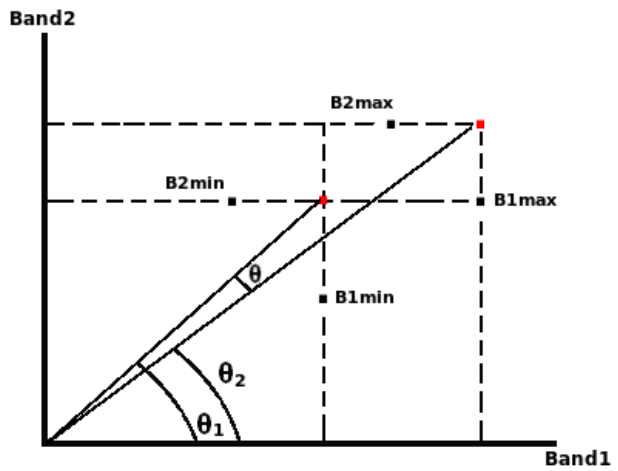

Figure 3. Spectral Contrast Shift (SCS) method.

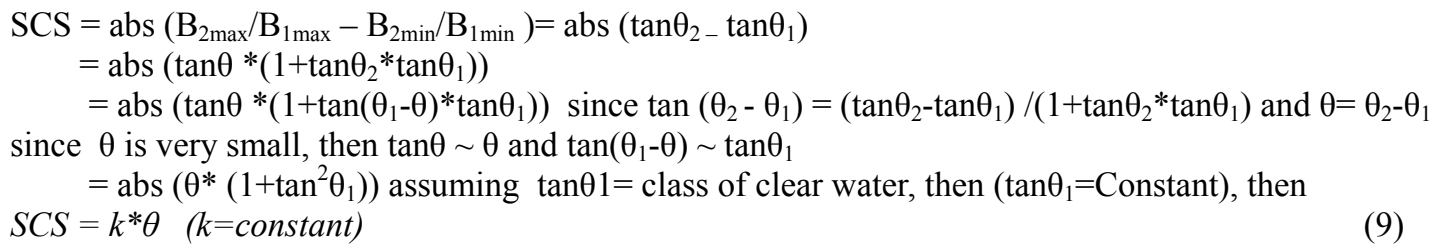

Alternatively, the (SCS) method can be viewed as a measures of the spectral contrast shift of a target from the surrounding clear water.

$$
\begin{aligned}
& \mathrm{SCS}=\operatorname{abs}\left(\mathrm{B}_{2 \max } / \mathrm{B}_{1 \max }-\mathrm{B}_{2 \min } / \mathrm{B}_{1 \min }\right)=\operatorname{abs}\left(\mathrm{B}_{2 \max } / \mathrm{B}_{1 \max }\left(1-\mathrm{B}_{1 \max } / \mathrm{B}_{2 \max } * \mathrm{~B}_{2 \min } / \mathrm{B}_{1 \max }\right)\right. \\
& \quad=\operatorname{abs}\left(\mathrm{B}_{2 \max } / \mathrm{B}_{1 \max }\left(1-\mathrm{C}_{2} / \mathrm{C}_{1}\right)\right) \\
& \text { where } \mathrm{C}_{1}(\text { contrast at band } 1)=\mathrm{B}_{1 \min } / \mathrm{B}_{1 \max }, \mathrm{C}_{2}(\text { Contrast at band } 2)=\mathrm{B}_{2 \min } / \mathrm{B}_{2 \max }, \\
& \quad=\operatorname{abs}\left(\mathrm{C}_{1} / \mathrm{C}_{12} *\left(1-\mathrm{C}_{2} / \mathrm{C}_{1}\right)\right)
\end{aligned}
$$

where $\mathrm{C}_{12}$ (inter-band contrast between bands 1 and 2 ) $=\mathrm{B}_{2 \min } / \mathrm{B}_{1 \max }$, assuming: $\mathrm{B}_{2 \min }=\mathrm{k}^{*} \mathrm{~B}_{1 \max }$, then $\mathrm{C}_{12}=\mathrm{k}$ where $\mathrm{k}=$ constant, then

$S C S=a b s\left(k^{*} \Delta C\right)$ where $\Delta C=C_{1}-C_{2}$ 
The Region of Interest (ROI) from which the minimum and maximum values are to be determined, should adhere to the following criteria as shown in Figure 4. in order for equation (8) to yield valid values:

a- It should include two classes only one of which should be clear water;

b- It should be small enough to ensure that the two classes are experiencing the same conditions like sun glint;

c- Areas where scanner lines are visible should be avoided so not to affect the overall accuracy of calculations;

and

d- Cloud shadows should be excluded since they may be mistaken for oil [16].

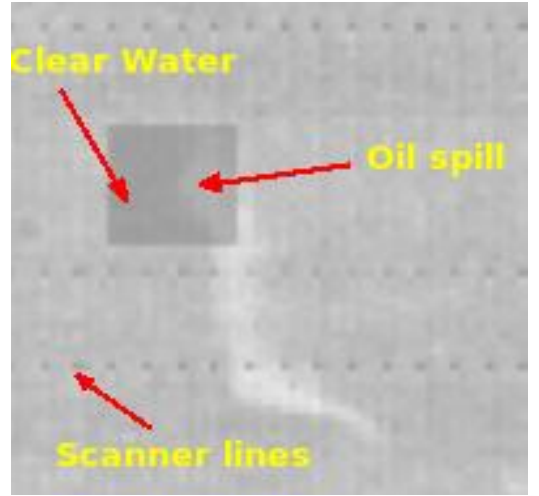

Figure 4. An example of the Region of interest (ROI) for the SCS method.

Depending on where the ROI is located on the spill region, the SCS may yield different values for different parts of the same spill, which reflect the its inhomogeneity. Improved detection accuracy can be achieved when the operators' prior familiarity with the general shape structure of the oil spill is coupled with the GIS information related to oil platform locations and daily tanker routes.

\subsection{Oil spills not under the sun glint}

\section{RESULTS}

An incident was captured during the day by the Terra satellite on 21 October 2007. Figures 5. and 6. correspond to images derived using equations (1) and (2) respectively. Figure 6. shows the natural colour composite of our first confirmed case of an oil spill not under direct sun glint.

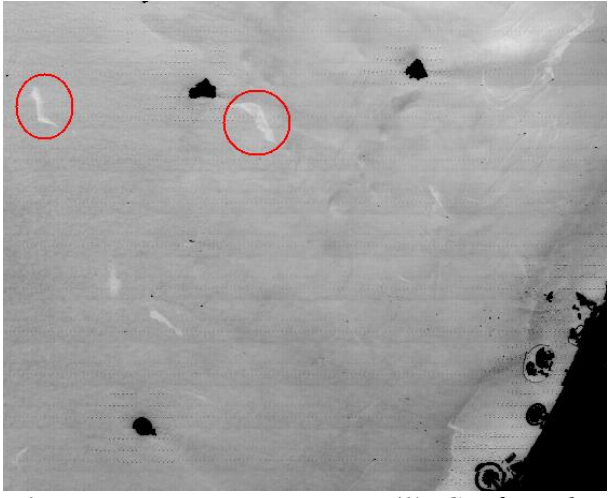

Figure 5. Depicting equation (1). Confirmed oil spill area are circled. Land appears black including islands.

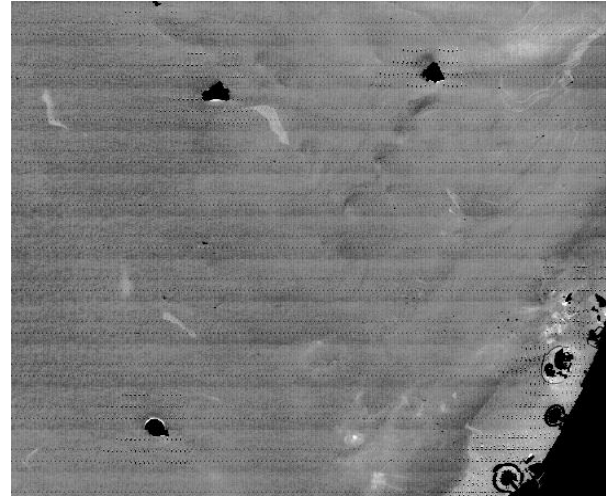

Figure 6. Depicting equation (2) for the oil spill incident area. Land appears black including islands. 


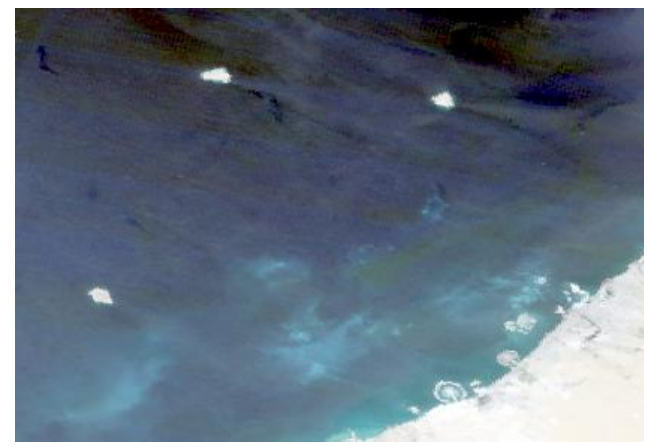

Figure 7. Natural colour composite 1,4,3 at $500 \mathrm{~m}$ resolution for the oil spill incident area.

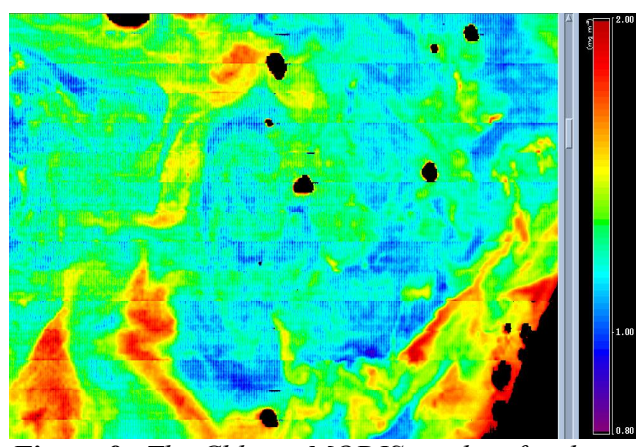

Figure 8. The Chlor-a MODIS product for the oil spill incident area.

Figure 7. Shows the standard Chlor-a product generated for the oil incident at $250 \mathrm{~m}$ resolution, where the oil spill pattern is not visible. This is probably because the oil layer is thin enough to have its radiance ratios similar to the surrounding, non-impacted waters, therefore the resulting chlorophyll estimates are similar. Figure 9. shows a false colour composite of the $250 \mathrm{~m}$ bands (RGB 2,1,1) of an area, where the surface algal blooms appear as reddish filaments on the water surface. This colour composite is similar in effect to the MCI (Maximum Chlorophyll Index) which was used by Gower and King (1993) to discriminate floating and coastal vegetation, as well as intense surface plankton blooms in the Gulf of Mexico using MERIS[5]. Cyanobacteria ${ }^{5}$ is an example of an oil look-alike algal species common in the RSA environment similar to the one shown in Figure 10. Figure 11. Shows the same false colour composite of the same oil spill, where pure oil appears as dark and not red, indicating that it is not a surface algal bloom.

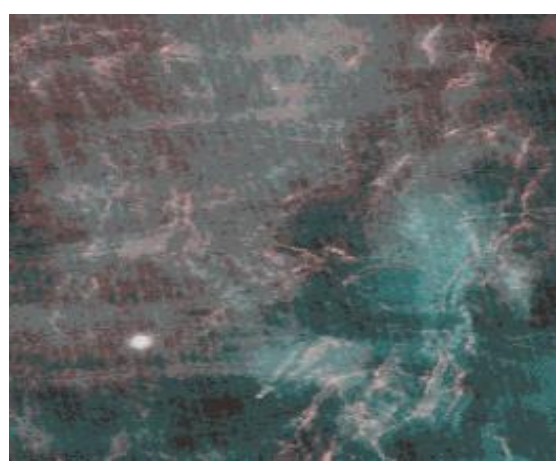

Figure 9. False $R G B$ colour composite 2,1,1 at 250m resolution. Surface algal blooms appear in red colour due to absorption of $869 \mathrm{~nm}$ infra-red band.

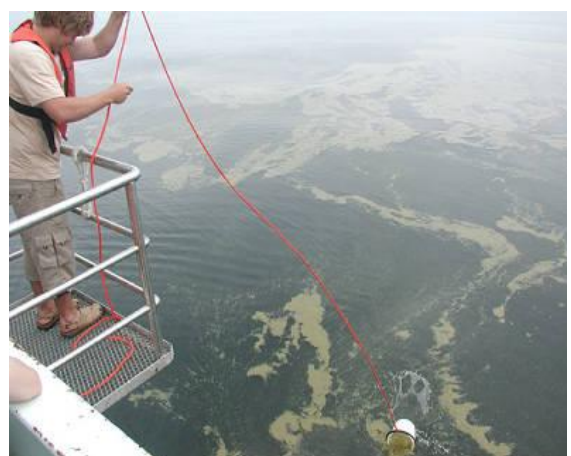

Figure 10. Typical shape of Cyanobacteria on sea surface. (courtesy: Aimar Rakko from University of Tartu)

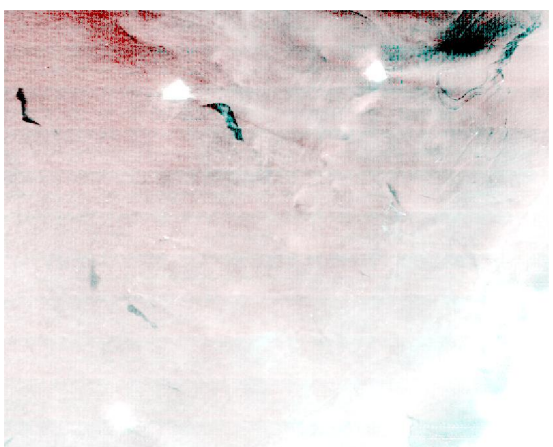

Figure 11. False RGB colour composite $2,1,1$ at $250 \mathrm{~m}$ resolution for the oil spill incident area.

5 Cyanobacteria used to be called "blue-green algae", but they are actually large photosynthetic bacteria. They may be blue-green, yellow-green, brown, or even reddish-purple. Many are motile. Some produce slime sheaths. They can produce thick and extensive mats. Frequently join into long filaments. 
Figure 12. shows the standard SST produced as shown in equation (3). Figure 13. shows the standard SST4 produced as shown in equation (4) for the same incident area.

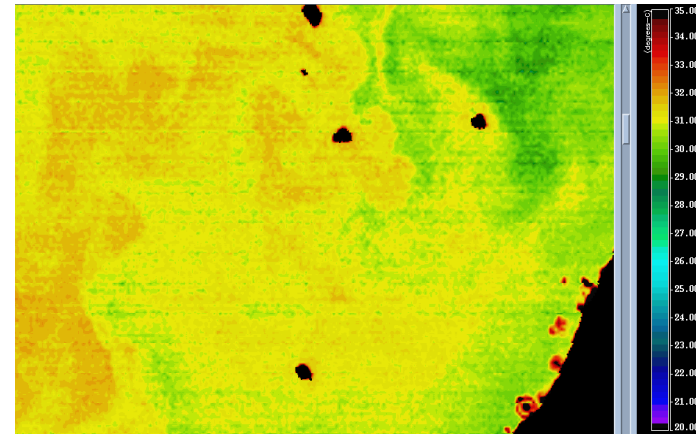

Figure 12. Sea Surface temperature at 11 and $12 \mu \mathrm{m}$ emissive bands (SST) product for the oil spill incident.

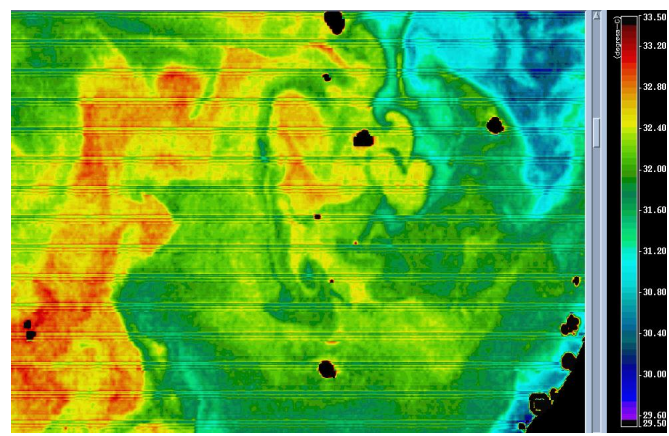

Figure 13. Sea Surface temperature at 3.959 and 4.050 m emissive bands (SST4) product, during the 'day' of the oil spill.

This generally indicates that oil temperature gradient, with respect to the water background is very low or non-existent. The short-wave infrared bands at 3-4 $\mu \mathrm{m}$ are affected by bright reflective sources such as sun glint. Due to such contamination, the short-wave SST product is not considered valid for daytime use [1]. However, some inferences about sea surface dynamics and structure may still be possible, as it is clearly shown in Figure 13. Figure 14. Shows the experimental output product in equation (7). Figure 15. shows the location of the confirmed oil spill incident plus the unreported ones discovered from the SCS calculations that were later verified through in-situ observation such as point 6. Table (2) summarises the results for all the points in Figure 15, which were analyzed according to the criteria outlined earlier.

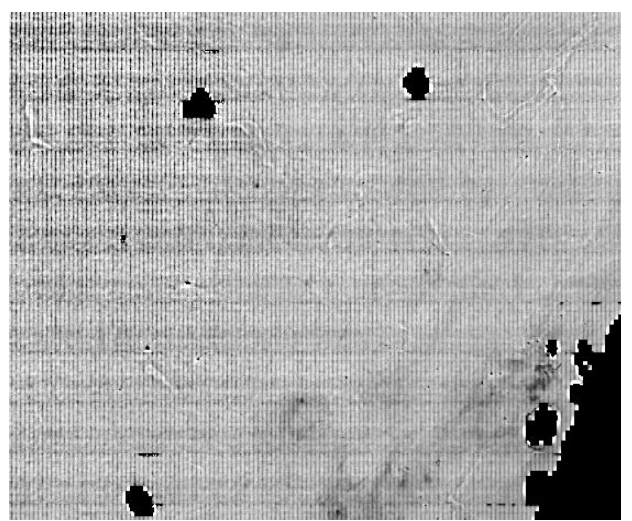

Figure 14. Depicting equation (7) for the oil spill incident.

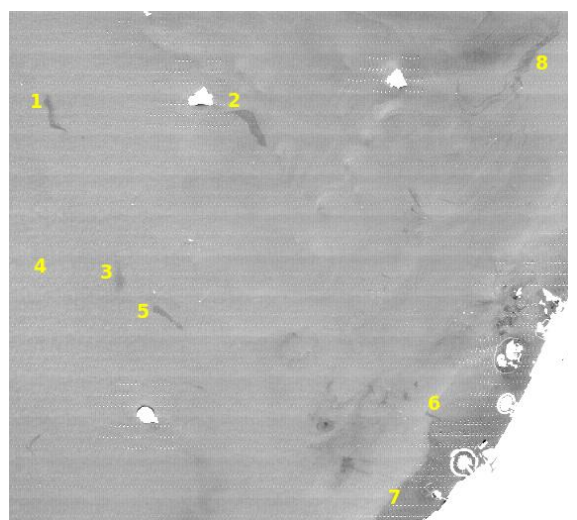

Figure 15. Position of the various suspected patches including oil spills where equation (8) was applied. This image was created using equation (1). 


\begin{tabular}{|l|l|l|l|l|l|l|}
\hline $\begin{array}{c}\text { Location } \\
\text { Number }\end{array}$ & \multicolumn{1}{|c|}{$\max 2$} & $\max 1$ & $\min 2$ & $\min 1$ & \multicolumn{1}{|c|}{ SCS } & \multicolumn{1}{|c|}{ Classification } \\
\hline 1 & 6.64 & 17.14 & 5.38 & 15.49 & 0.04 & Oil \\
\hline 2 & 6.70 & 17.59 & 5.4346 & 15.78 & 0.04 & Oil \\
\hline 3 & 7.12 & 18.22 & 5.976 & 16.72 & 0.03 & Sheen \\
\hline 4 & 7.60 & 19.38 & 6.85 & 17.88 & 0.01 & Water \\
\hline 5 & 7.23 & 18.51 & 5.91 & 16.62 & 0.04 & Oil \\
\hline 6 & 8.21 & 20.71 & 6.49 & 18.22 & 0.04 & Oil \\
\hline 7 & 8.37 & 20.37 & 6.54 & 18.33 & 0.05 & Turbid area \\
\hline 8 & 6.86 & 17.88 & 5.52 & 15.88 & 0.04 & Oil \\
\hline
\end{tabular}

Table (2). The output results of equation (4) conducted on the point numbers shown in Figure (15).

\subsection{Oil spills under the sun glint}

Figure 16. shows the natural colour composite for the confirmed case of an oil spill next to a sun glint. This incident was captured during the day by the Aqua satellite on 25 May $2005^{6}$. Figure 17. shows the depiction of the incident as in equation (2).

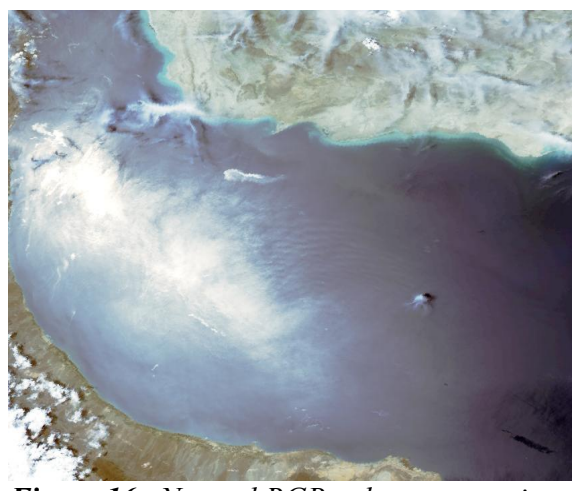

Figure 16. Natural RGB colour composite $1,4,3$ at $500 m$ resolution of oil spill.

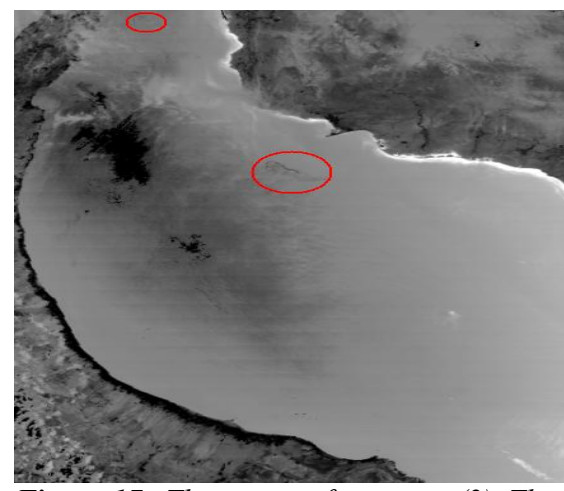

Figure 17. The output of equation (2). The confirmed oil spill areas are circled.

Atmospheric conditions such as density distribution of dust particles (aerosols) and the geometry relationship between the viewing angle and sun glint direction led to the failure of producing the following MODIS standard products for this oil spill incident: nlw_869, nlw_645 and chlor-a. However, a false colour composite similar to Figure 9. was created for this spill incident area but the spill patches did not appear in reddish colour due to the infra-red absorption, which indicates that the spill was not a surface plankton bloom. This can also be supported by the operators' prior experience with regard to the shape differences that exist between oil spills and surface plankton blooms.

6 Tanker M/V Astro Lupus collided with RoRo M/V Safari in the Gulf of Oman on May 23, 2005. The hull of the tanker was damaged, with 500 tons of crude oil leaking into the sea. 


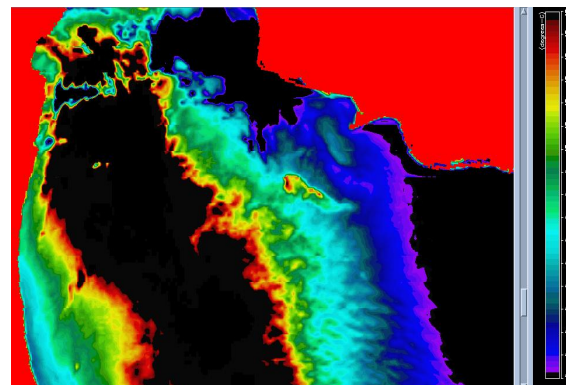

Figure 18. The SST4 product during the Day for the oil spill incident.

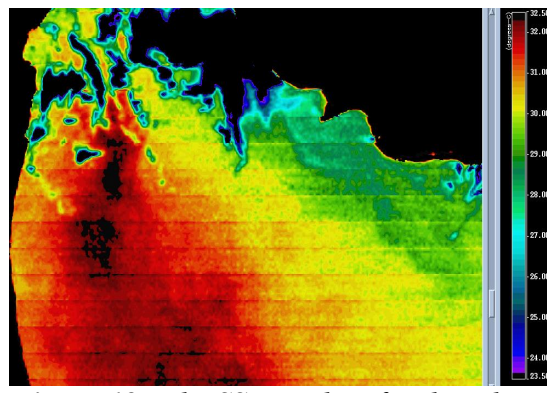

Figure 19. The SST product for the oil spill incident.

Similarly, the applicability of equation (7) was not possible due to the lack of production of nlw_869 and nlw_645. Figure 18. and Figure 19. respectively show the SST4 (day) and SST MODIS products. In Figures 16 . and 18. the oil spill appears hotter (brighter) because of its high reflectance from the sun glint as a result of the higher refractive index of the relatively thin oil layer.

Figure 20. shows the location of the various suspected patches including confirmed oil spills incidents, were the SCS was calculated. The results are summarised in Table (3) for all points, and analyzed according to the criteria outlined earlier.

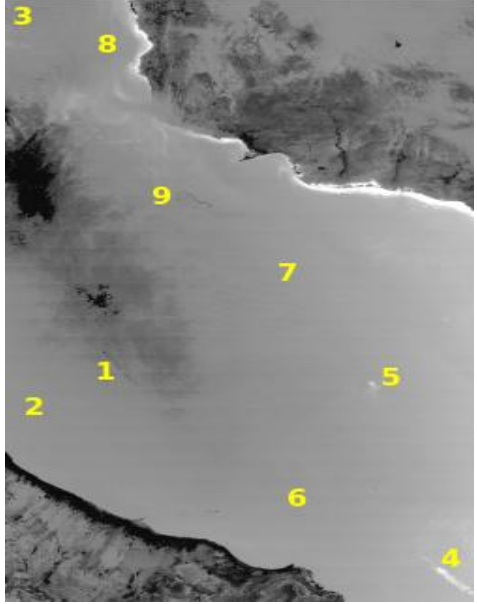

Figure 20. Position of various suspected patches including the confirmed oil spills. This image was created using equation (2).

\begin{tabular}{|l|l|l|l|l|l|l|}
$\begin{array}{l}\text { Location } \\
\text { Number }\end{array}$ & $\max 2$ & $\max 1$ & $\min 2$ & $\min 1$ & $\mathrm{SCS}$ & Classification \\
\hline 1 & 183.26 & 265.24 & 69.747 & 106.22 & 0.03 & Sheen \\
\hline 2 & 100.69 & 153.56 & 52.35 & 83.72 & 0.03 & Sheen \\
\hline 3 & 78.49 & 114.69 & 47.64 & 73.90 & 0.04 & Oil \\
\hline 4 & 20.37 & 37.98 & 8.99 & 21.70 & 0.10 & Unclassified \\
\hline 5 & 32.19 & 54.17 & 20.93 & 38.84 & 0.06 & Unclassified \\
\hline 6 & 59.80 & 93.60 & 35.78 & 59.66 & 0.04 & Oil \\
\hline 7 & 51.54 & 80.93 & 40.59 & 65.54 & 0.02 & Ballast water \\
\hline 8 & 73.86 & 112.79 & 41.94 & 68.04 & 0.04 & Oil \\
\hline 9 & 154.85 & 230.42 & 46.00 & 72.75 & 0.04 & Oil \\
\hline
\end{tabular}

Table (3). The output results of equation (4) conducted on the point numbers shown in Figure (20). 


\section{CONCLUSION}

Although MODIS is incapable of revealing the spectral signature of oil, it successfully demonstrated the ability to discriminate oil spills using the $250 \mathrm{~m}$ resolution bands $645 \mathrm{~nm}$ and $869 \mathrm{~nm}$ - provided certain atmospheric conditions exist. Environmental conditions like cloud-free skies and calm sea state that are found in the ROPME region, contribute to the success of MODIS and promote it as a cost effective early warning system against marine pollution. The region however, suffers from two occasional atmospheric conditions that hinder MODIS from observing oil spills and other marine phenomena: dust storms and clouds.

Two methods were investigated that show promising results in providing accurate detection of marine oil spills. Both methods exploit the minute difference in spectral response between the red and I.R. bands at the $250 \mathrm{~m}$ resolution towards the biophysical structures occurring at the sea surface.

The first is related to using some of the existing standard MODIS L2 products to differentiate between genuine oil spills and oil spill look-alikes. The (chlor-a) product was used to investigate the visibility of the oil pattern, provided that the oil spill is thick enough to alter the plankton biomass properties in the water column. The false RGB colour composite of the $250 \mathrm{~m}$ resolution bands $2,1,1$ was also used to eliminate surface algal blooms as oil due to their appearance in red as a result of I.R. absorption. The ( $\mathrm{nl} w)$ was another standard MODIS product which was utilized to delineate the spill pattern in finding the difference between the nlw_869 and nlw_645 MODIS products.

Generally, oil spills exhibits negligible temperature difference with respect to the background sea surface. Although the SST4 product is valid during the night, its production during the day can nevertheless, provide basic classification to the different layers of the oil spill due to their different reflectance response from the sun with respect to the sea surface background.

The second newly derived method, the Spectral Contrast Shift (SCS), is a robust classification method independent from varying radiometric conditions. SCS depends on measuring the deviation between an unknown class on the water surface from clear water by using the different responses between the red $(645 \mathrm{~nm})$ and I.R. $(869 \mathrm{~nm})$ bands that exist within the MODIS $250 \mathrm{~m}$ resolution channels. This method proves to be successful in identifying oil spills ${ }^{7}$ including other sea surface phenomena as outlined in Table (4). This work may lead towards setting up a classification library for identifying different sea surface structures. It also stands as a good candidate to be considered for any future automatic detection applications. The main disadvantage of this method is the spectral mixture problem when choosing the ROI or the limitation in pixel numbers. The concept behind the SCS algorithm can also be adopted in other sensors than MODIS.

\begin{tabular}{|c|c|}
\hline SCS & Classification type \\
\hline 0.004 & Fire Plume \\
\hline 0.01 & Water \\
\hline 0.02 & Ballast water \\
\hline 0.03 & Sheen \\
\hline 0.04 & Oil \\
\hline 0.05 & Turbid water \\
\hline 0.20 & Surface Algae \\
\hline
\end{tabular}

Table (4). The Spectral Contrast Shift (SCS) values for some common marine surface phenomenons including oil.

7 During the writing of this paper, the SCS technique managed to identify two an unconfirmed oil spills that were later confirmed to be the case via in-situ observations. 


\section{REFERENCES}

[1] Franz, B.,"Implementation of SST Processing within the OBPG," http://oceancolor.gsfc.nasa.gov/DOCS/modis_sst/ (2006).

[2] Brekkea , C., Solbergb and A. H.S., "Oil spill detection by satellite remote sensing," Remote Sens. Environ. 95(1), 1-13 (2005).

[3] Crosta, A.P., Sabine, C. and Taranik, J.V., "Hydrothermal Alteration Mapping at Bodie, California, using AVIRIS Hyperspectral Data," Remote Sens. Environ. 65, 309-319 (1998).

[4] Fingas, M., and C. Brown, "Oil-spill remote sensing -- an update," Sea Technol. 41, 21-26 (2000).

[5] Gower, J., King, S., Borstad, G. and Brown L., "Detection of intense plankton blooms using the $709 \mathrm{~nm}$ band of the MERIS imaging spectrometer," Int. J. Remote Sens. 26, 2005-2012 (2005)

[6] Reid, J., Piketh, S., Kahn, R., Bruintjes, R. and Holben B., "A Summary of First Year Activities of the United Arab Emirates Unified Aerosol Experiment: UAE2," Naval Research Laboratory, 10 (2005).

[7] Kahru, M., Mitchell, B., Diaz, A. and Miura, M., "MODIS Detects Devastating Algal Bloom in Paracas Bay, Peru," EOS Trans. AGU, 85 (45), 465-472 (2004).

[8] Carder, K., Chen, F., Lee, Z., Hawes, S. and Cannizzaro, J., "MODIS Ocean Science Team Algorithm Theoretical Basis Document, ATBD 19, Case 2 Chlorophyll a," University of South Florida, (2003).

[9] Kruse, F.A., Boardman, J.W., Lefkoff, A.B., Heidebrecht, K.B., Shapiro, A.T., Barloon, P.J. and Goetz, A.F.H., "The Spectral Image Processing System (SIPS) - Interactive Visualization and Analysis of Imaging Spectrometer Data," Remote Sens. Environ. 44, 145-163 (1993).

[10] ROPME, [Kuwait Regional Convention for Cooperation on the Protection of the Marine Marine Environment and the Coastal Areas of Bahrain, Iran, Iraq, Kuwait, Oman, Qatar, Saudi Arabia and United Arab Emirates, Kuwait], ROPME, 5 (1978).

[11] Li, R., Kaufman, Y.J., Gao, B. and Davis, C.O., "Remote Sensing of Suspended Sediments and Shallow Coastal Waters," IEEE Trans. on Geoscience and Remote Sens., Vol. 41(3), 559 (2003).

[12] MEMAC, [MEMAC (The Marine Emergency Mutual Aid Centre) Biennial Report (2003-2005)], MEMAC, 49 (2005).

[13] Miller, R.L. and McKee, B.A., "Using MODIS Terra $250 \mathrm{~m}$ imagery to map concentrations of total suspended matter in coastal waters," Remote Sens. Environ. 93, 259-266 (2004).

[14] Maccherone, B., http://modis.gsfc.nasa.gov

[15] Richards, J.A., [Remote Sensing Digital Image Analysis], Springer-Verlag, Berlin, 340 (1994).

[16] Byfield, V., "Optical Remote Sensing of Oil in the Marine Environment - PhD Thesis," University of Southampton, Ch. 8, 218- 243 (1998). 